\title{
How to Achieve the Best Treatment of Tibial Occlusive Disease? Early Experience in Benha University Hospitals
}

\author{
EL-SAYED A. ABD EL-MABOOD, M.D. and MOHAMED T. YOUNIS, M.D. \\ Vascular Unit, The Department of General Surgery, Faculty of Medicine, Benha University
}

\begin{abstract}
Background: The treatment of constructable tibial occlusive disease has changed dramatically because of the advent of catheter-based interventions. However, surgical bypass techniques continue to evolve in response to increasingly complex scenarios such as failed endovascular procedures.

Aim of Study: To achieve the best treatment using the endovascular intervention versus distal bypass in constructable tibial occlusive disease.

Patients and Methods: This prospective randomized controlled study was done on 40 patients (60 limbs) assigned into two groups, each group contains 30 limbs. Group A 30 limbs prepared for distal surgical bypass. Group B 30 limbs prepared for endovascular intervention. Follow-up period was for 18 months.
\end{abstract}

Results: Despite endovascular intervention had equal patency rates at 6 th month as distal surgical bypass; 21 limbs $(70 \%), p=1.000$. It was much less than surgical bypass in morbidities; in Group A 11 limbs (36.7\%) didn't develop complications and 19 limbs (63.3\%) underwent complications. In Group B 25 limbs (83.3\%) passed without complications and 5 patients $(16.7 \%)$ with complications; less post-operative pain; pain score in Group (A) was $(5.95 \pm 1.99)$ vs. $(2.9 \pm 1.93)$ in Group (B) and $p$-value: 0.001 .

Conclusions: Due to innovations in endovascular techniques and as it is a minimal invasive; proudure angioplasty became the first line of treatment of BK PAD. Endovascular intervention treat the lesion and keep the arterial tree with its native anatomical pattern so angioplasty can be done again if restenosis occur. Unlike surgical intervention in which it's too difficult to re-interfere after surgical bypass.

Key Words: Distal bypass - Endovascular intervention Tibial occlusive disease.

\section{Introduction}

CRITICAL Limb Ischemia (CLI) is a limb-and life-threatening condition with a yearly incidence of around 220 new cases per million population.

Correspondence to: Dr. El-Sayed A. Abd El-Mabood, Vascular Unit, The Department of General Surgery, Benha University
Below the knee atherosclerotic is the most common cause of CLI, usually due to multilevel and diffuse arterial disease with compromised foot arteries run-off $[1,2]$.

The risk of limb loss within 1 year is estimated to be $70 \%$ in the presence of rest pain and $95 \%$ if there is tissue loss. Lower limb amputations, $70 \%$ of them in diabetics. About $80 \%$ of all major amputations may be preventable with the use of new interventional and vascular surgical procedures, particularly on the arteries of the leg and foot $[3,4]$.

The goals of treatment of Below Knee (BK) chronic limb ischemia are: To provide pain relief, promote wound healing, and preserve limb function. The two available interventions, bypass surgery (BSX) and balloon angioplasty (BAP), have generally been considered to have a number of relative advantages and disadvantage $[\mathbf{5 , 6 ]}$.

In the treatment of Below Knee (BK) chronic limb ischemia, percutaneous intervention is an excellent modality, given the appropriate patient and the fast-evolving technology. The procedure was recommended based on guidelines to treat TASC A and B lesions, but is increasingly used as first-line therapy regardless of the TASC status [7]

In recent years, Percutaneous Transluminal Angioplasty (PTA) has become the first-line option in the treatment of (CLI), as it allows the healing of ulcers. The primary goal of PTA treatment is to restore the patency of at least one below the knee vessel, preferably the tributary of the anatomical region of the ulcer $[\mathbf{8 , 9}]$

Thus, although surgery remains a good option for some patients with CLI, endovascular therapy offers the advantages of local anesthesia and potentially reduced costs (even anticipating the need for re-intervention in many patients) and shorter 
hospital stays when compared with surgical bypass [10].

Characteristically diabetic occlusive lesion involve the infra popliteal arteries with calcific single or multiple stenoses and occlusions, more than above knee arteries. In more than $90 \%$ of patients one or more of BK arteries spared [11].

There are several reasons for the rapid growth of endovascular revascularization. First, endovascular interventions fall under the broad category of minimally invasive surgery, making it more attractive to patients. In the past, patients with critical limb ischemia would have undergone surgical revascularization provided their general condition allowed it; if not, they would either receive no treatment or perhaps undergo an amputation. Second, repeated endovascular interventions might be required to sustain long-term patency. This translates to the fact that patients may undergo multiple endovascular revascularizations as opposed to a single surgical bypass. Furthermore, patients with failed bypass grafts who have undergone endovascular revascularization have shown significant improvement in terms of limb salvage rates $[\mathbf{8 , 9 , 1 2 ]}$.

As most of patients with CLI often present with multi-segment occlusive disease, "Chong et al." [13] reported that to effectively treat these multisegments, bypass surgery remains the most effective modality. It can bypass the most extensive occlusive disease provided there is an adequate inflow, suitable vein conduit and an adequate run-off artery at or beyond the ankle. The potential gain from a successful tibial PTA is obvious, even if repeated procedures are needed. However, the results of PTA for infrapopliteal arteries have been disappointing, even for less extensive lesions, but this may change as coronary technology can be increasingly applied to the treatment of below-knee disease.

The current study included 40 patients who underwent Below Knee (BK) revascularization. Patients were divided into two Groups (A \& B) each group consisted of 20 patients. The clinical outcome of surgical vs endovascular revascularization was evaluated for a period of 18 months post revascularization.

\section{Patients and Methods}

After Local Ethical Committee of Benha University approval and obtaining written fully informed patients consent, forty patients with man- ifestations of lower limb ischemia due to below Knee (BK) PAD, admitted to the Vascular Unit in Departments of Surgery in Benha University Hospital, were considered for inclusion in this study from November 2015 till May 2018 so as to allow 18 months follow-up period for the last case operated on.

This prospective randomized controlled study was conducted on 40 patients (60 limbs) assigned into two groups, each group contain 20 patients (30 limbs); 10 patients with unilateral BK PAD and 10 patients with bilateral BK PAD. Group A 30 limbs prepared for distal surgical bypass. Group B 30 limbs prepared for endovascular intervention. Patients were assigned into each group through computerized randomized controlled study.

Patients included in this study were suffering from CLI, foot ulcer or trophic changes, patient with rest pain, patient with infragenicular PAD with or without supragenicular lesion and patients with any BK morphological lesion.

But patients excluded from this study who were unable to provide consent due to incapacity (mental disability), who were judged unsuitable for either of the two revascularization strategies (i.e. arteritis), Tissue loss considered to be primarily of venous etiology, full thickness gangrene of the foot, widespread of infection of the lower limb, symptomatic Coronary Artery Disease (CAD) or Cerebral Vascular Disease (CVD); who require interventional management first; had anticipated life expectancy less than 6 months, or if there were contraindications of contrast as; severe renal failure or known allergy to iodinated contrast agents.

All patients underwent evaluation by complete history taking about personal data, risk factors (smoking, DM, hypertension, hyperlipidemia), comorbidities (previous stroke, angina, MI and CKD), previous PAD interventions to one or both legs, previous amputation, history of presenting symptom (rest pain or tissue loss) and previous coronary intervention (CABG, PCI). Then full clinical examination for blood pressure, Assessment of functional status (independent stick walker, prosthesis, wheelchair or bed-bounded), recording of peripheral pulses, measurement of ABPI, wound assessment (in those patients with tissue loss), assessment of ischemic night/rest pain and assessment of claudication distance.

Pre procedural investigations included laboratory investigation; routine biochemistry (creatinine, estimated GFR, ESR, CRP, RBS, cholesterol, 
HBA1c), routine hematology (hemoglobin, white cell count, platelet count, HbA1c), PT, PTT, INR and lipid profile. Imaging by one or more of the following; duplex ultrasound, Computerized Tomography Angiography (CTA), Magnetic Resonance Angiography (MRA) and Digital subtraction angiography (DUS).

\section{Techniques of intervention:}

I- Surgical bypass (Group A):

Procedures performed under general, spinal, epidural anesthesia or combined general and epidural anesthesia. As epidural anesthesia after revascularization reduce platelet aggregation, decrease peripheral vascular resistance, and increase the graft flow, but carry the risk of epidural hematoma. Pre-operative I.V antibiotics were given 30 minutes prior to skin incision to ensure adequate tissue levels at time of incision. Autogenous great saphenous veins were used in all procedures. Duplex mapping of the GSV was routinely performed in all patients before surgery; if the ipsilateral GSV is absent, unsuitable, or of insufficient length for the anticipated bypass, the contralateral great saphenous vein examined to locate a suitable vein. The veins that used were soft, compressible, and at least $3 \mathrm{~mm}$ in diameter. Calcified or sclerotic veins or veins with small diameter were rejected.

In reversed saphenous graft, vein harvesting was performed through long continuous incisions or through skip incision harvest of the vein was began with a groin incision two finger breadths lateral to pubic tubercle. The sapheno-femoral junction was exposed to ensure the GSV. Then the incision was extended distally. Side branches were ligated and divided close to the main trunk. The vein was completely exposed and mobilized through a continuous incision or multiple skin bridges incision. After exposure of adequate length, it was ligated and prepared by gently irrigation and distension with heparinized saline. Small avulsed branches were repaired by prolene $6 / 0$ or $7 / 0$.

Then, proper graft tunneling of reversed vein grafts was done in a deep anatomic plane to avoid kinking and graft exposure incase of wound complications. In proximal and mid posterior tibial and peroneal bypasses an anatomic tunnel between two heads of gastrocnemius was done. For bypasses to anterior tibial the tunnel was done through interosseus membrane.

But In situ vein bypass, the proximal segment of GSV was initially mobilized in the groin. The distal segment was exposed at the level of distal anastomosis. Exposure of femoral artery by longitudinal incision over the CFA and extend to SFA and profunda femoris. Inflow and outflow vessels should be exposed, and the vein graft prepared, prior to anticoagulation and arterial clamping. Surgical exposure of target artery varies depending on the target vessel and location of the distal anastomosis.

The tibioperoneal trunk and proximal tibial vessels were exposed through a medial approach below the knee, avoiding injury to the greater saphenous vein during the skin incision. The muscular fascia was incised and the medial head of the gastrocnemius muscle was retracted postrolateral. The medial head of the gastrocnemius was divided in some cases.

After target vessel exposure and vein harvest, intravenous heparin was given prior to arterial clamping at a dose of 70-100 units/kg and was redosed at 45 minute intervals as needed to maintain an Activated Clotting Time (ACT) of 250-300. Gentle clamping techniques should be employed using nontraumatic vascular clamps to minimize the possibility of clamp injury. Anastomoses were performed using small diameter (6-0 or 7-0) monofilament suture. The proximal anastomosis was performed first. Reversed saphenous vein bypasses were usually tunnelled in the deeper anatomic plane. Attention must be paid to avoid graft twisting or kinking.

After completion of the anastomoses and flow restoration, the adequacy of perfusion is assessed by inspection of the foot and toes, palpation of distal pulses and Doppler flow assessment in the bypass graft and outflow artery. Non-infected foot wounds greater than $2 \mathrm{~cm}$ may be debrided at the end of the operation after arterial reconstruction. Debridement may include toe amputations which may be loosely closed Figs. (1A-F).

\section{II- Endovascular procedure (Group B):}

All patients were admitted one day before intervention or on the same day. All endovascular interventions were done in the angiosuite (Philips; Allura X per FD 20/722028164) Fig. (7), C-arm image intensifier with road mapping was used.. All patients should already be on a chronic aspirin regimen. Clopidogrel was started 5 days before the procedure, or a $300 \mathrm{mg}$ load was administrated periprocedure. Patients were placed in supine position. Both groins were prepared using antiseptic solution povidone iodine $(7.5 \%)$. The procedures were done under local anaesthesia (xylocaine $2 \%$ : 
$3-5 \mathrm{mg} / \mathrm{kg}$ ); sometimes combined with sedation in irritable patients.

The arterial access was planned after reviewing of the pre-operative imaging. The BTK vessels were accessed through either: Antegrade ipsilateral common femoral artery puncture or contralateral femoral puncture and performing a crossover technique. The choice depended on anatomy and the.

Associated edlesions. After gaining access a $6 \mathrm{~F}$ sheath is inserted and free arterial flow is allowed to confirm the right position of the sheath. Angiography is done to confirm data obtained by pre-operative investigations using nonionic low osmolar dye diluted to $50 \%$ with normal saline. The lesions were identified. Systemic anticoagulation with heparin 5000IU.

Procedural tools were a 6-f introducing sheath, a 4-f angiographic angled tip catheter 'Bernstein', 0.035 hydrophilic guide-wire 'zip wire standard, terumo wire regular, NitrixTM' for simple stenoses, 0.018 guide-wire 'BS V-18TM' control wire for tibials and 0.014 guide-wire 'Abbott PilotTM' for pedal arteries, long tibial balloons low-profile with diameters ranging from $2-4 \mathrm{~mm}$ (less than $4 \mathrm{~F}$ ) designed for BK purposes 'Amphirion/Invatec, Admiral'. They are made to work on a 0.014 " or a 0.018 ". Crossing the lesion: To cross BK stenoses, guide-wires were used for cross the lesion transluminal or subintimal. We penetrate the proximal occlusion followed by negotiation the full extent of the occlusion, until the distal patent lumen. A drilling motion of the guide-wire was performed to properly penetrate and cross the lesion. Often times, a short and low profile coaxial catheter balloon can be used as a support catheter.

Then, balloons with diameter 2-3.5mm were used with inflation pressure 8-10 ATM. Inflation time was 2 minutes for arterial segment dilatation. As the balloon inflates, assessment of the roadmap image should confirm that the balloon catheter was appropriately sized. After balloon deflation 100ug of nitroglycerin were injected intra-arterially injected. In cases that paclitaxel Drug Coated Balloon (DCB) was used. Balloon crosses the lesion and cover it then inflated for 3-5 minutes.

Completion angiogram was performed routinely and successful revascularization was considered when at least one anterior or posterior tibial artery with residual stenosis less than $30 \%$ and clinically restoration of pulse and warmness. Lastly, routinely sheath was removed after procedure completion with digital compression for 15 minutes and delay mobilization for 12 hours. In case of heparin dose $>5000 \mathrm{IU}$ sheath removal was postponed until aPTT normalized. Hemostasis achieved by manual compression. Digital compression was held proximal to the skin puncture site for 15-20 minutes and mobilization was delayed for 6-12 hours Figs. (2A-D).

Post procedure management: All patients were given post-operative therapeutic anticoagulation by enoxaparin in addition to broad spectrum antibiotics and analgesia. The patients received foot care consisting of wound dressing, minor debridement, limited amputations (up to transmetatarsal amputation), infection control, and appropriate footwear before discharge. Patients discharged after receiving instructions on risk factors control Both groups were maintained on cilostazol $100 \mathrm{mg}$ twice/day, acetylsalicylic acid $150 \mathrm{mg} /$ day and/or clopidogrel $75 \mathrm{mg} /$ day after hospital discharge for 3-6 months.

Post procedural follow-up: Progress of limb conditions after intervention were observed regarding: Diminution or absence of rest pain, healing of ulcers, improvement of ABI, improvement of claudication distance, limb salvage and patency of grafts were recorded for each patient. Patency of the grafts was determined by palpation of the pulses in the foot. Doppler ultrasonography was performed if the pulse was not palpable. The intensity of postoperative pain was assessed using a Visual Analogue Scale (VAS); it is the most sensitive scale for measuring treatment characteristics. The respondents were asked to assess their pain intensity between the end-points of no pain to worst possible pain on the scale $[\mathbf{1 4 , 1 5}]$. Any complications were recorded whether general or local wound complication as puncture site hematoma, pseudoaneurysm, flow limiting dissection, bleeding, thrombosis, failure of procedure or recurrent stenosis. All patients were followed for 18 months with regular visits at 3,6,12 and 18 months from the date of intervention or when new complaints arise. Follow-up consisted of clinical examination \pm imaging study (if needed in cases of absent pulse).

Statistical analysis: The collected data will tabulated and presented in suitable figures; quantitative data will be summarized using mean and standard deviation, while, qualitative data by using frequency and percentage. Data will be analyzed by the aid of software package of SPSS using suitable statistical tests. The accepted level of significance in this work will be 0.05 ( $p<0.05$ will be considered significant). 


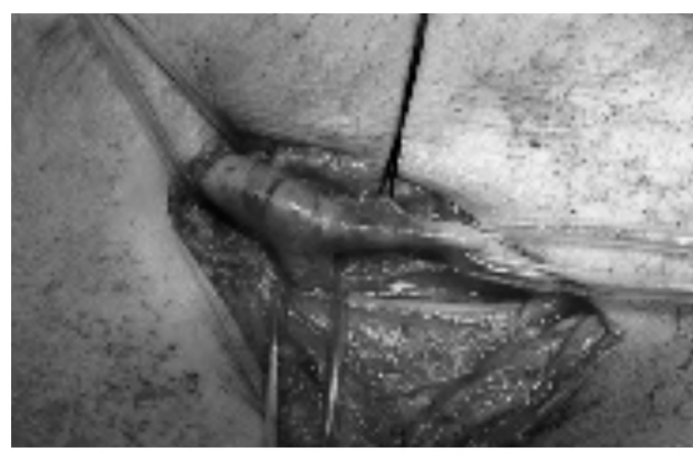

Fig. (A): Femoral artery exposure.

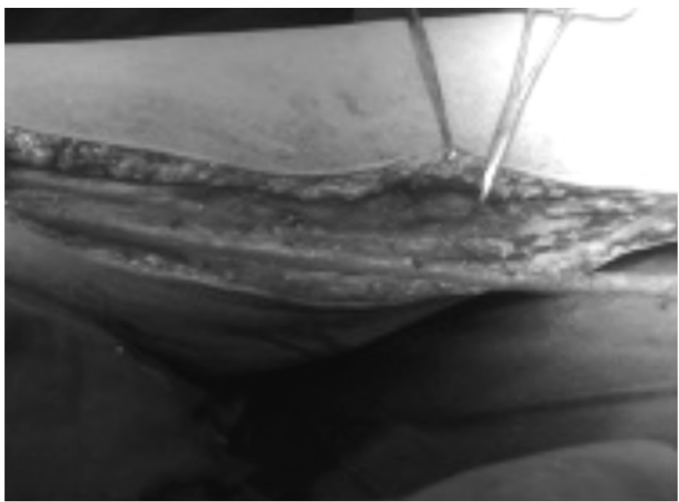

Fig. (C): Harvesting of great saphenous vein.

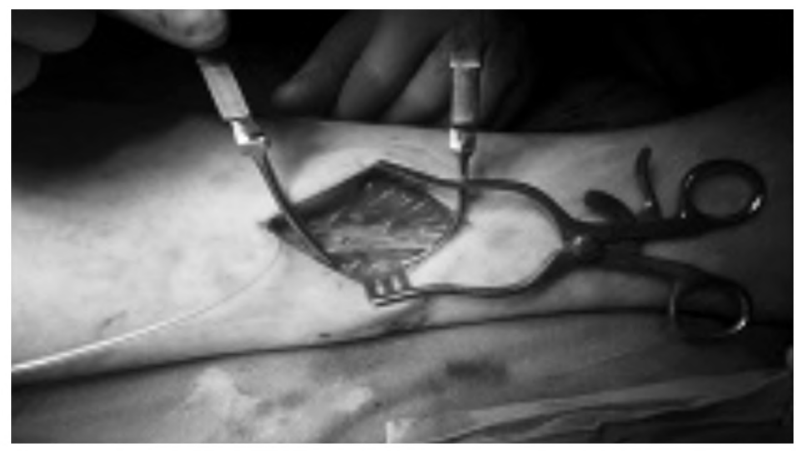

Fig. (B): Posterior tibial artery exposure.
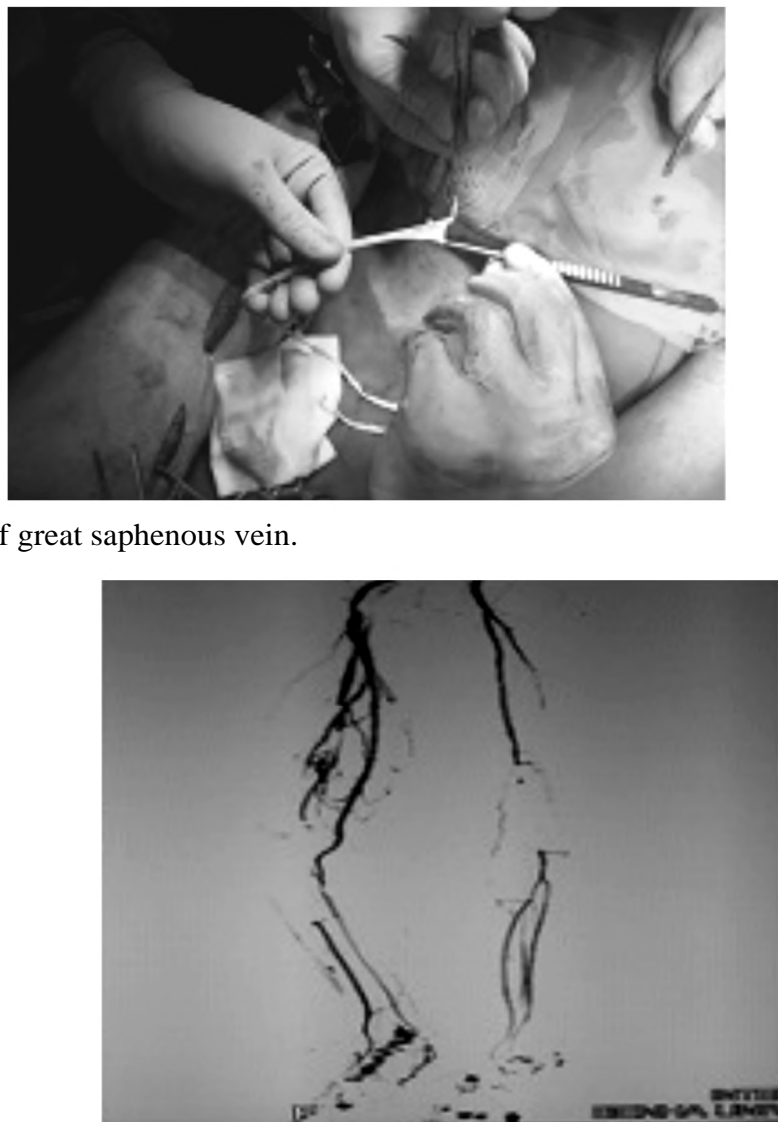

Fig. (E): Post intervention CT angiography.

Fig. (D): Posterior tibial anastomosis.
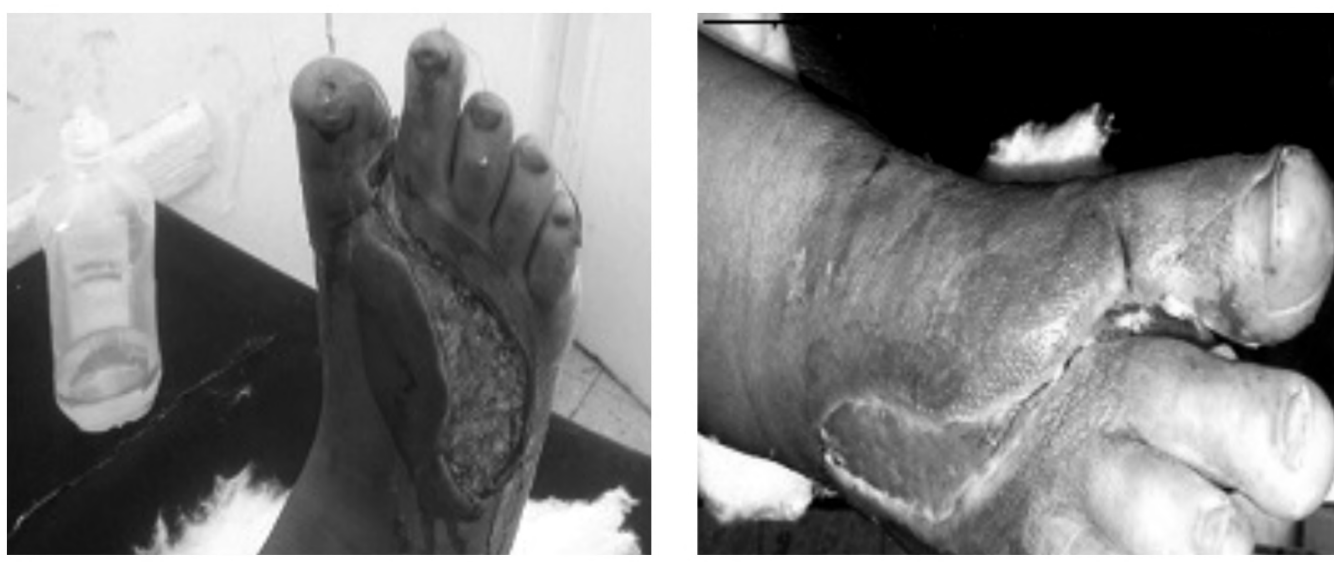

Fig. (F): Debridement of planter aspect of foot post revascularization and 1 month after. Fig. (1A-F): Steps of surgical bypass. 

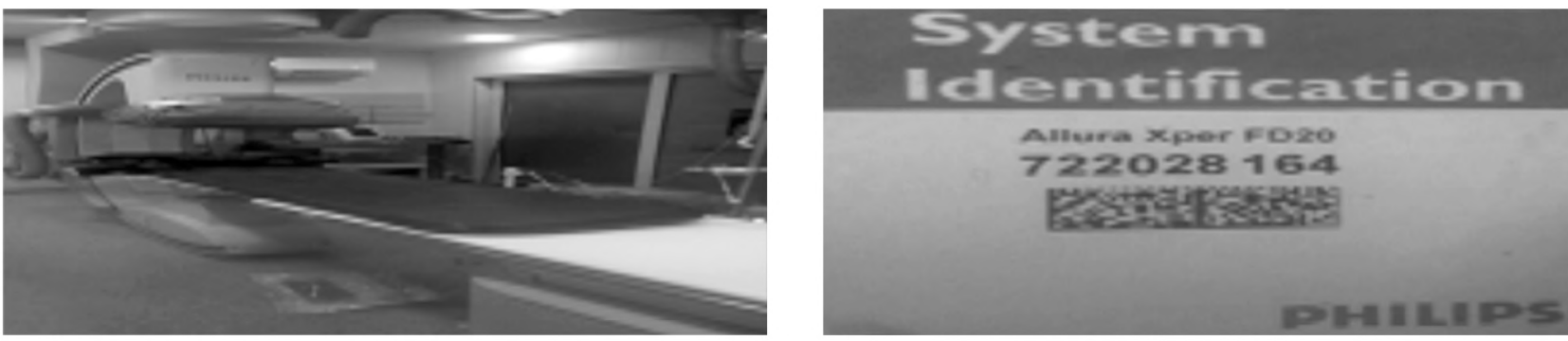

Fig. (A): Angio suite (Philips; Allura X per FD 20/722028164).

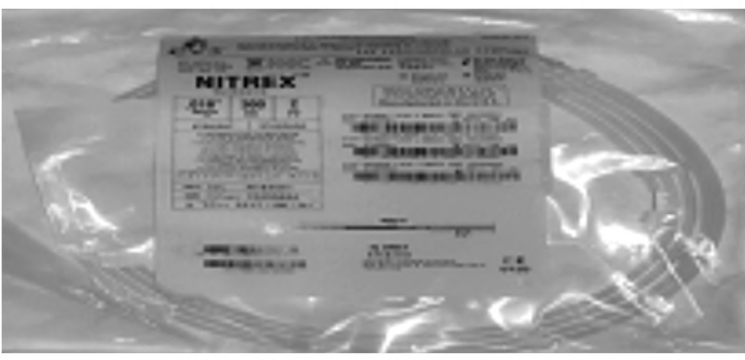

0.018 'NitrixTM' guide wire.

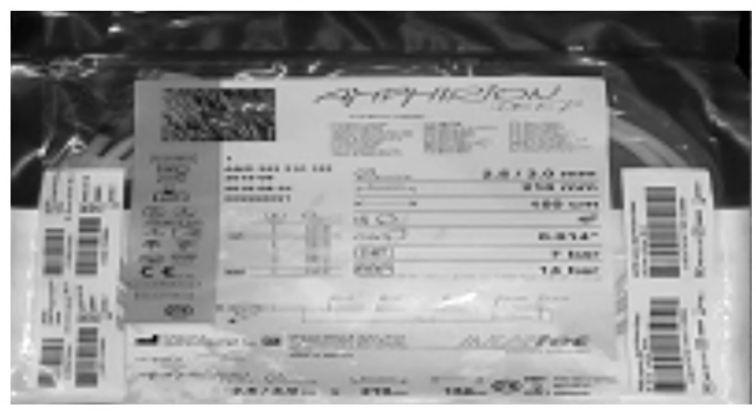

Balloon catheter 'Amphirion' 2.5mm X 210mm

Fig. (B): Guide wires \& Balloon catheter used in this study.
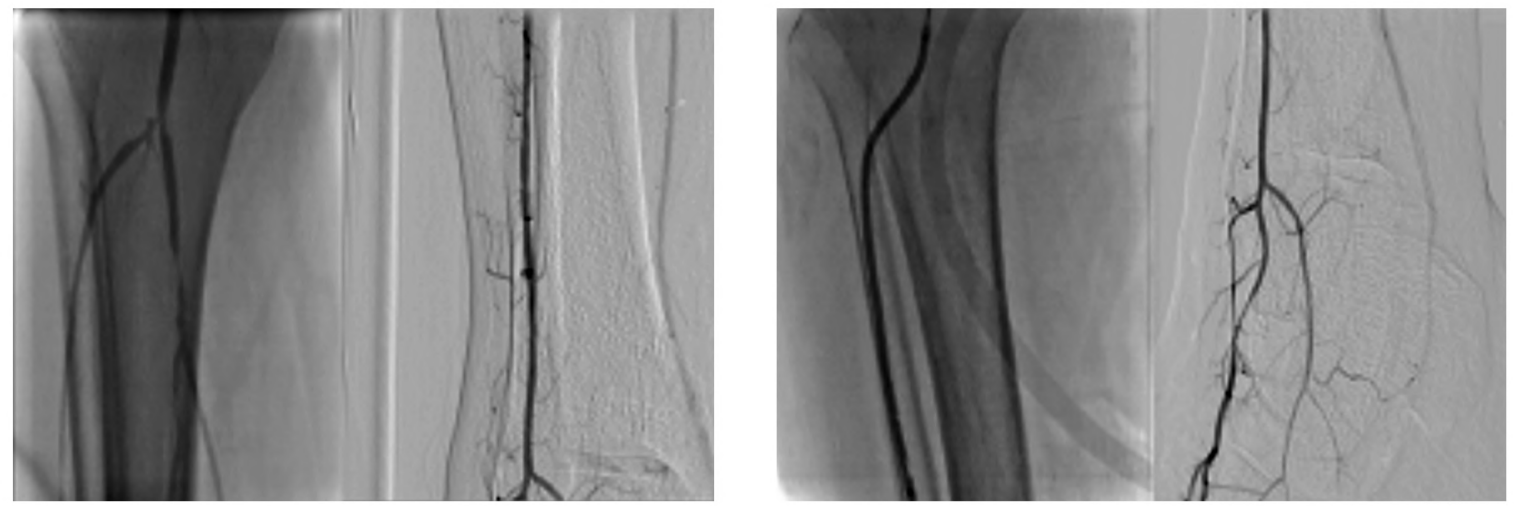

Fig. (C): Anterior \& posterior tibial artery balloon dilatation.
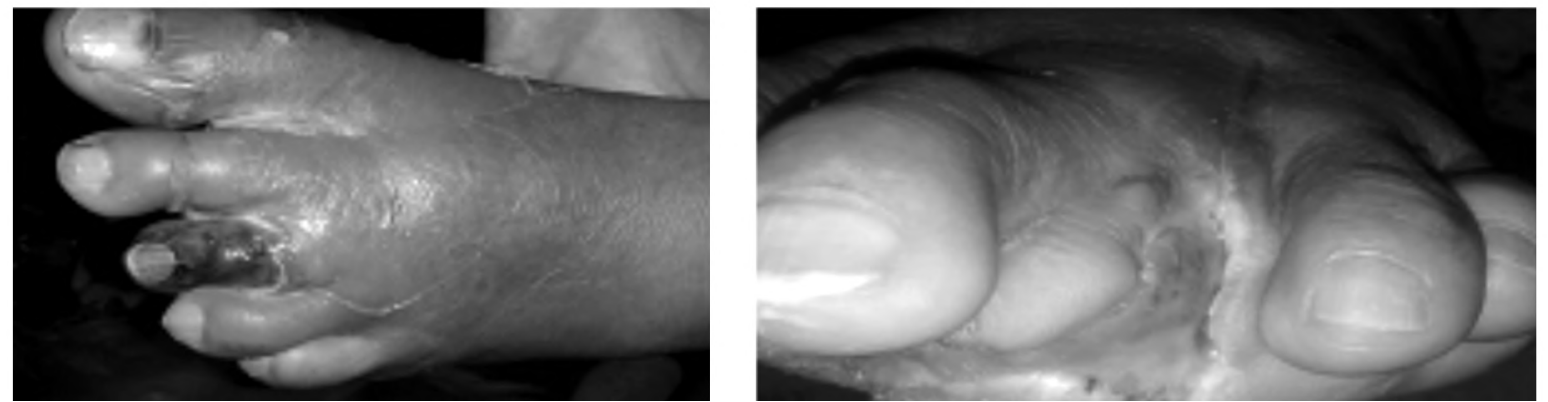

Fig. (D): Ray's amputation of gangrenous third toe 1 month after revascularization. Fig. (2A-D): Steps of endovascular procedure. 


\section{Results}

This prospective randomized controlled study was conducted on 40 patients assigned into 2 groups, each group contain 20 patients complaining manifestations of lower limb ischemia due to Below Knee (BK) PAD, 29 (72.5\%) males and 11 (27.5\%) females with age over 40 years with strata; $41-50$ years: 13 (32.5\%), 51-60 years: $27(67.5 \%)$ and $>60$ years: 19 (47.5\%); collected from Vascular Unit of General Surgery Departments, Benha University Hospitals (Table 1), Graph (1).

Table (1): Patients demographic data.

\begin{tabular}{llc}
\hline \multirow{2}{*}{ Data } & \multicolumn{2}{c}{ Findings } \\
\cline { 2 - 3 } & Number $(\%)$ & Mean \pm SD (range) \\
\hline Age (years): & & \\
Strata: & & \\
$41-50$ & $9(22.5 \%)$ & $57.2 \pm 3.2$ \\
$51-60$ & $12(30 \%)$ & $54.6 \pm 1.2$ \\
$>60$ & $19(47.5 \%)$ & $65.3 \pm 3.9$ \\
\hline Total & $40(100 \%)$ & \\
\hline Gender: & & \\
Females $ᄋ$ & $11(27.5 \%)$ & \\
Males $0^{\top}$ & $29(72.5 \%)$ & \\
\hline - Data are presented as numbers \& mean \pm SD; percentages are in \\
parenthesis
\end{tabular}
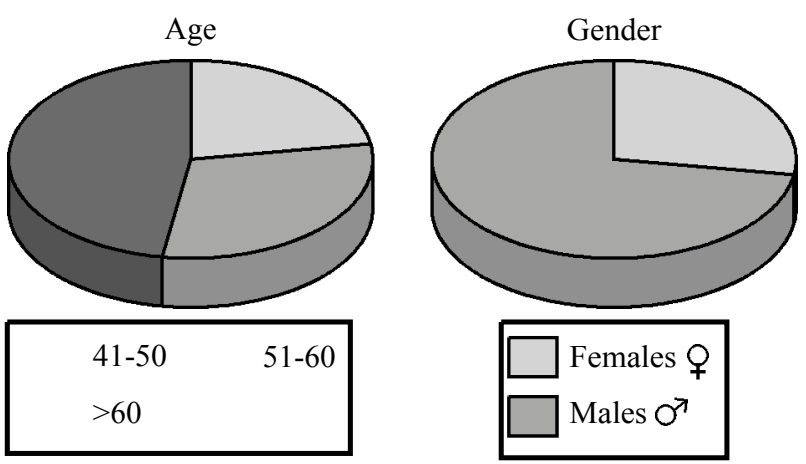

Graph (1): Patients demographic data.

The presenting symptoms were: In Group A: 5 patients (25\%) had rest pain (Rutherford 4), 10 patients $(50 \%)$ had minor tissue loss (Rutherford 5 ) and 5 patients (25\%) had major tissue loss (Rutherford 6). In Group B: 4 patients (20\%) had rest pain (Rutherford 4), 10 patients $(50 \%)$ had minor tissue loss (Rutherford 5) and 6 patients $(30 \%)$ had major tissue loss (Rutherford 6) (Table 2), Graph (2).

Patients were classified according to lesion morphology through TASC lesion classification 2015 into TASC A, B, C and D as: In Group A: No patient with TASC A classification, 4 patients
(20\%) with TASC B classification, 10 patients $(50 \%)$ with TASC C classification, 6 patients $(30 \%)$ with TASC D lesion classification. In Group B: 3 patients $(15 \%)$ with TASC A classification, 5 patients $(25 \%)$ with TASC B classification, 7 patients (35\%) with TASC C classification, 5 patients $(25 \%)$ with TASC D lesion classification (Table 3), Graph (3).

Table (2): Clinical presentation (Rutherford classification) in both groups.

\begin{tabular}{|c|c|c|c|c|c|c|}
\hline \multirow{2}{*}{ Rutherford } & \multicolumn{2}{|c|}{$\begin{array}{c}\text { Group A } \\
(\mathrm{n}=20 \text { patients })\end{array}$} & \multicolumn{2}{|c|}{$\begin{array}{c}\text { Group } B \\
(\mathrm{n}=20 \text { patients })\end{array}$} & \multirow{2}{*}{$\begin{array}{l}\text { Test } \\
\text { of sig. }\end{array}$} & \multirow{2}{*}{$p$} \\
\hline & No. & $\%$ I & No. & $\%$ & & \\
\hline R4 & 5 & 25.0 & 4 & 20.0 & & \\
\hline R5 & 10 & 50.0 & 10 & 50.0 & $\chi^{2}=$ & $\mathrm{FE}_{p}=$ \\
\hline R6 & 5 & 25.0 & 6 & 30.0 & 0.296 & 1.000 \\
\hline Min.-max. & $4.0-6.0$ & & $4.0-6.0$ & & & \\
\hline Mean \pm SD & $5.0 \pm 0.73$ & & $5.10 \pm 0.72$ & & 0.438 & 0.664 \\
\hline Median & 5.0 & & 5.0 & & & \\
\hline
\end{tabular}

$\chi^{2}: \chi^{2}$ and $p$-values for Chi square test for comparing between the two groups.

$\mathrm{FE}_{p}$ : $p$-value for Fisher Exact for Chi square test for comparing between the two groups.

$t, p: t$ and $p$-values for paired $t$-test for comparing between the two groups.

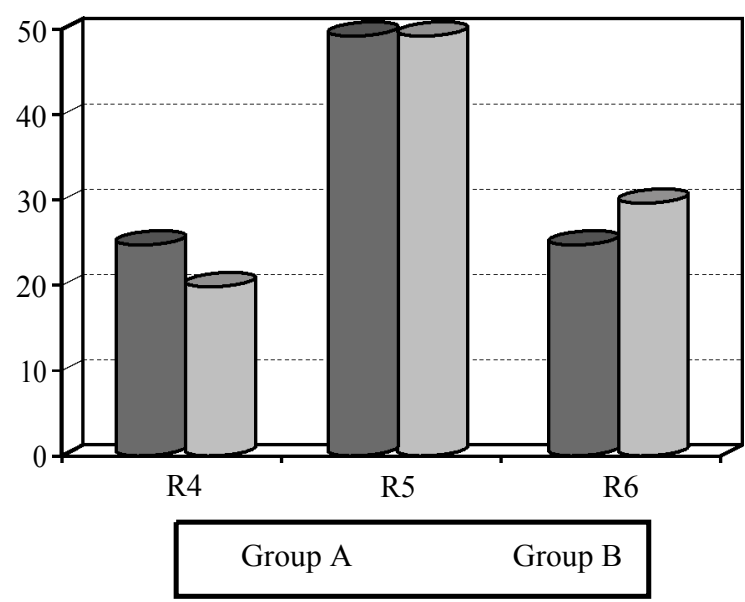

Graph (2): Clinical presentation (Rutherford classification) in both groups.

Table (3): Comparison between the two studied groups according to TASC.

\begin{tabular}{|c|c|c|c|c|c|c|}
\hline \multirow[t]{2}{*}{ TASC } & \multicolumn{2}{|c|}{$\begin{array}{c}\text { Group A } \\
(\mathrm{n}=20 \text { patients })\end{array}$} & \multicolumn{2}{|c|}{$\begin{array}{c}\text { Group } B \\
(\mathrm{n}=20 \text { patients })\end{array}$} & \multirow{2}{*}{$x^{2}$} & \multirow[t]{2}{*}{$\mathrm{MC}_{p}$} \\
\hline & No. & $\%$ & No. & $\%$ & & \\
\hline A & 0 & 0.0 & 3 & 15.0 & 3.411 & 0.407 \\
\hline B & 4 & 20.0 & 5 & 25.0 & & \\
\hline C & 10 & 50.0 & 7 & 35.0 & & \\
\hline $\mathrm{D}$ & 6 & 30.0 & 5 & 25.0 & & \\
\hline
\end{tabular}




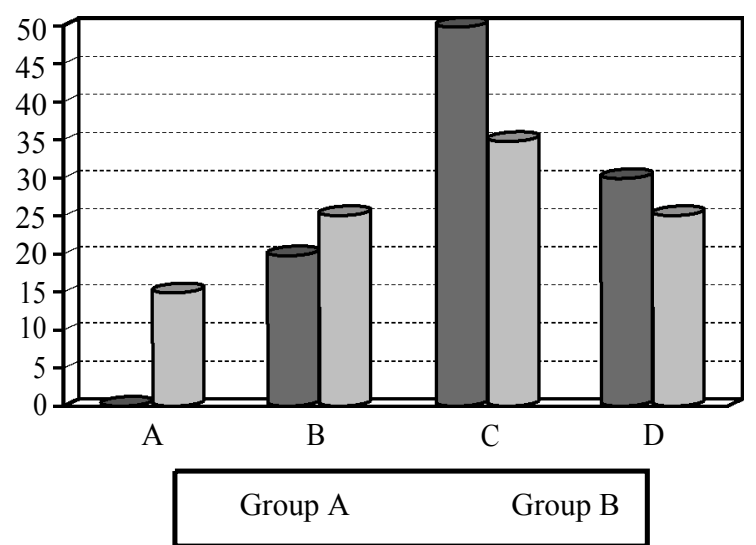

Graph (3): Comparison between the two studied groups according to TASC.

As regard to risk factors; 27 patients $(67.5 \%)$ were smokers, 31 patients $(77.5 \%)$ were diabetics, 29 patients $(72.5 \%)$ were Hypertensive (HTN), 19 patients $(47.5 \%)$ were ischemic heart disease (IHD), 24 patients $(60 \%)$ had hyperlipidemia (HLIP), 5 patients $(12.5 \%)$ had previous stroke and 11 patients $(27.5 \%)$ had previous peripheral angioplasty; distributed as follow (Table 4), Graph (4).

Table (4): Risk factors of both groups.

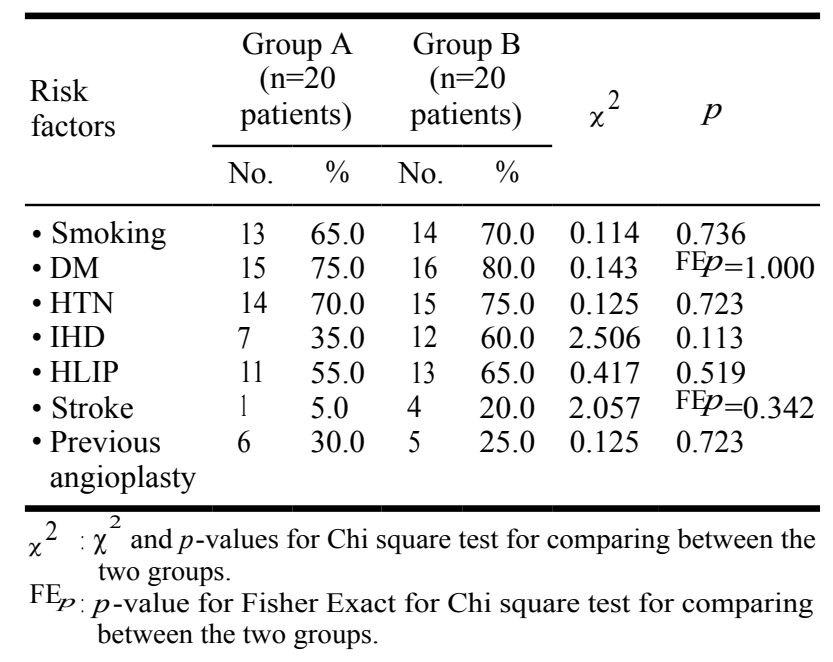

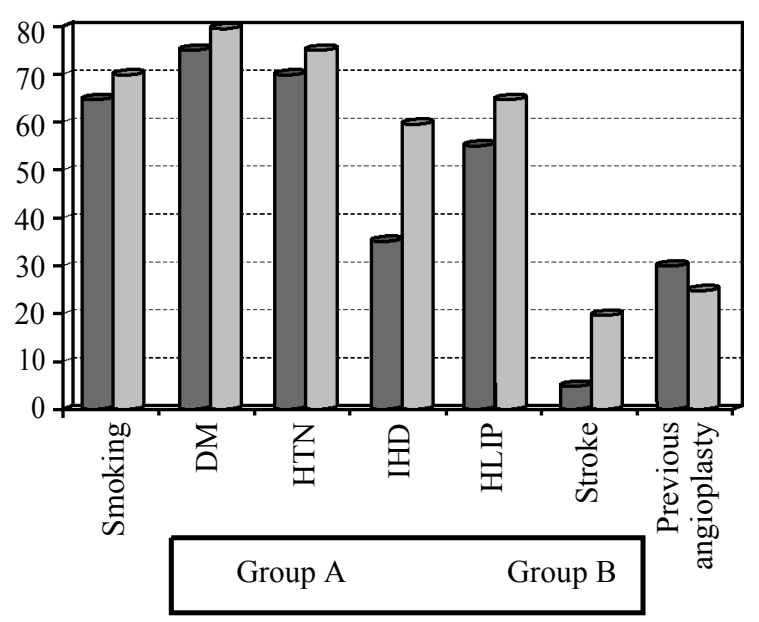

Graph (4): Risk factors of both groups.
All patients passed uneventful intra-operative course. Mean operative time was $175.6 \pm 3$; range: 160-191 minutes in Group (A) and $162.9 \pm 8$ range: 153-179 minutes in Group (B). Mean intraoperative blood loss was $659 \pm 1.3$; range: 550 $760 \mathrm{ml}$ in Group (A) and 540.2 \pm 6.9 range: 540 $750 \mathrm{ml}$ in Group (B). Patients in Group (A) were discharged 6-13 days Post-Operative (PO); but in Group (B) were discharged 1-2 days PO (Table 5), Graph (5).

Table (5): Operative and immediate Post-Operative (PO) data.

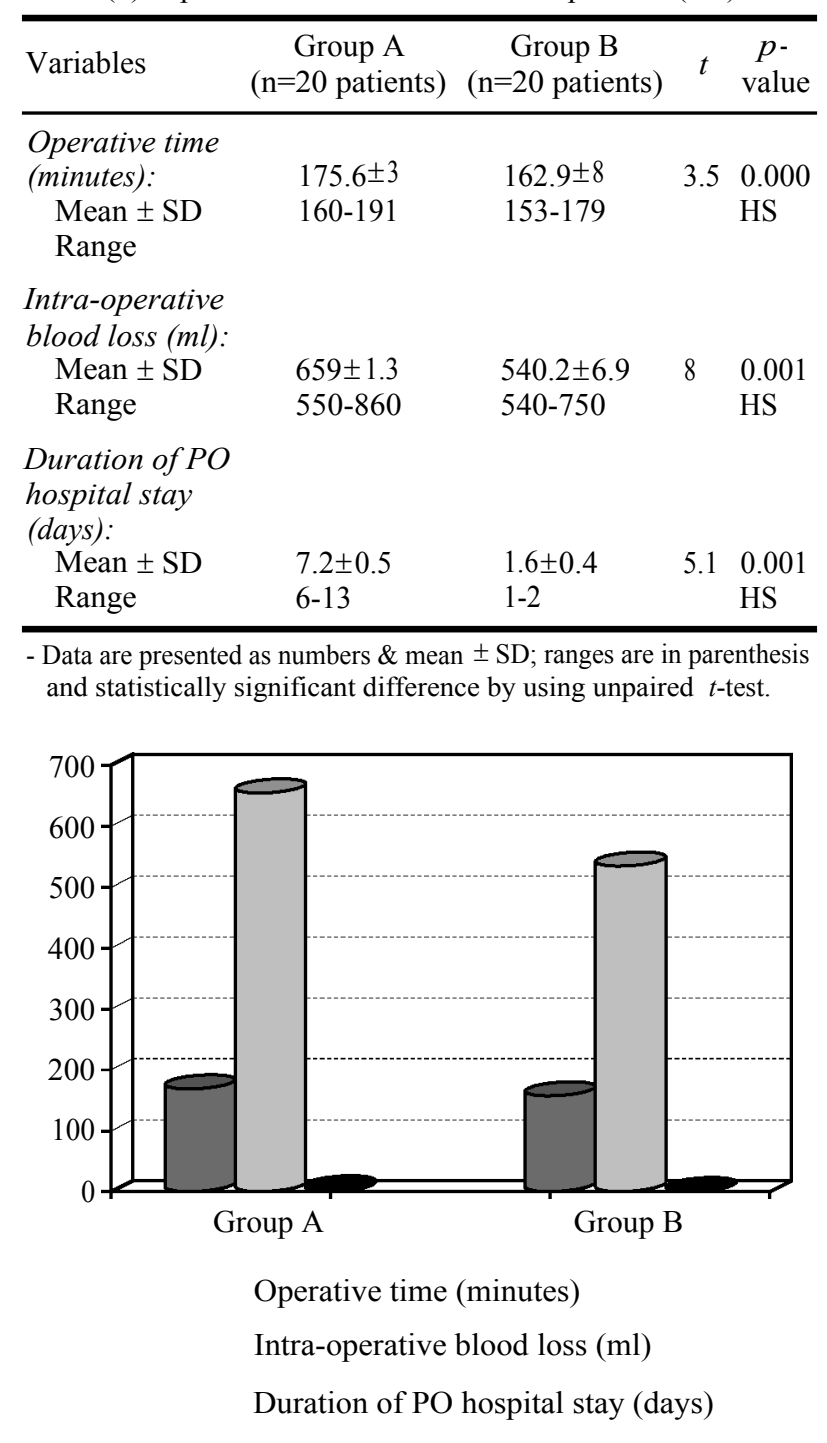

Graph (5): Operative and immediate Post-Operative (PO) data.

Post-operative pain was assessed for both group by using the Visual Analog Score (VAS); at 1 st 2 days; high significant difference between both groups was noticed; Group (A) average doses was $(11.9 \pm 1.2)$ vs. (4.3 \pm 1.9$)$ for Group (B) and pain score was $(5.95 \pm 1.99)$ vs. $(2.9 \pm 1.93) ; p$-value: 0.001 . Also this significant difference between 
both groups was noticed after 7 days (Table 6), Graph (6).

Table (6): Pain assessment using a Visual Analog Score (VAS).

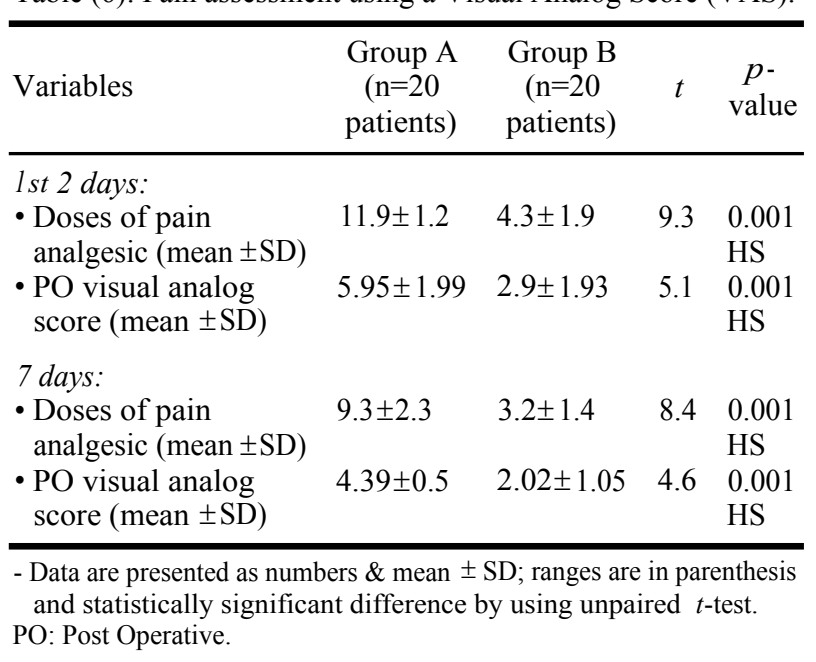

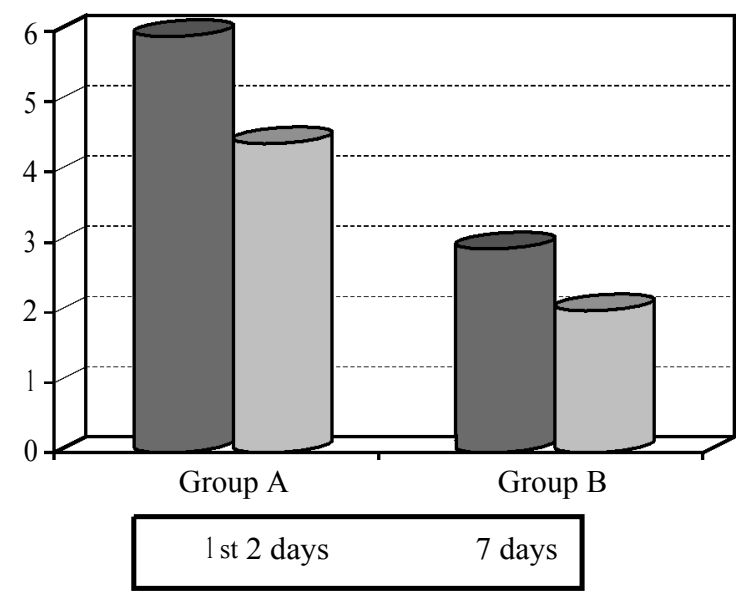

Graph (6): Post Operative Visual Analog Score (VAS).

Patency was assessed by palpation of distal pulses or radiologicaly. Patients were examined immediate post interventional, at 3, 6, 12 and 18 months. Patients with successful revascularisation, defined as functioning graft and intact limb. A limb was considered intact if major amputation could be avoided, no need for secondary amputation, healing of ulcer and disappearance of rest pain (Table 7), Graph (7).

As regard to complications: In Group A 11 limbs (36.7\%) passed without complications and 19 limbs $(63.3 \%)$ underwent complications. In Group B 25 limbs (83.3\%) passed without complications and 5 patients $(16.7 \%)$ with complications. Regarding to amputations, 7 limbs $(23.3 \%)$ of Group A underwent major amputation, but in group B 4 patients $(13.3 \%)$ underwent major amputation (Table 8).

Table (7): Comparison between the two studied groups according to patency.

\begin{tabular}{|c|c|c|c|c|c|c|}
\hline \multirow[t]{2}{*}{ Patency } & \multicolumn{2}{|c|}{$\begin{array}{c}\text { Group A } \\
(\mathrm{n}=30 \\
\text { limbs })\end{array}$} & \multicolumn{2}{|c|}{$\begin{array}{c}\text { Group B } \\
(n=30 \\
\text { limbs })\end{array}$} & \multirow[t]{2}{*}{$\chi^{2}$} & \multirow[t]{2}{*}{$p$} \\
\hline & No. & $\%$ & No. & $\%$ & & \\
\hline \multicolumn{7}{|l|}{ Immediate: } \\
\hline Occluded & 3 & 10.0 & 4 & 13.3 & 0.229 & $\mathrm{FE}_{p}=$ \\
\hline Patent & 27 & 90.0 & 26 & 86.7 & & 1.000 \\
\hline \multicolumn{7}{|c|}{ After 3 months: } \\
\hline Occluded & 7 & 23.3 & 4 & 13.3 & 0.625 & $\mathrm{FE}_{p}=$ \\
\hline Patent & 23 & 76.7 & 26 & 86.7 & & 0.695 \\
\hline \multicolumn{7}{|c|}{ After 6 months: } \\
\hline Occluded & 9 & 30.0 & 9 & 30.0 & 0.000 & $\mathrm{FE}_{p}=$ \\
\hline Patent & 21 & 70.0 & 21 & 70.0 & & 1.000 \\
\hline \multicolumn{7}{|c|}{ After 12 months: } \\
\hline Occluded & 10 & 33.3 & 11 & 36.7 & 0.114 & $\mathrm{FE}_{p}=$ \\
\hline Patent & 20 & 66.7 & 19 & 63.3 & & 0.736 \\
\hline \multicolumn{7}{|c|}{ After 18 months: } \\
\hline Occluded & 16 & 53.3 & 10 & 33.3 & 0.789 & $\mathrm{FE}_{p}=$ \\
\hline Patent & 14 & 46.7 & 20 & 66.7 & & 0.827 \\
\hline
\end{tabular}

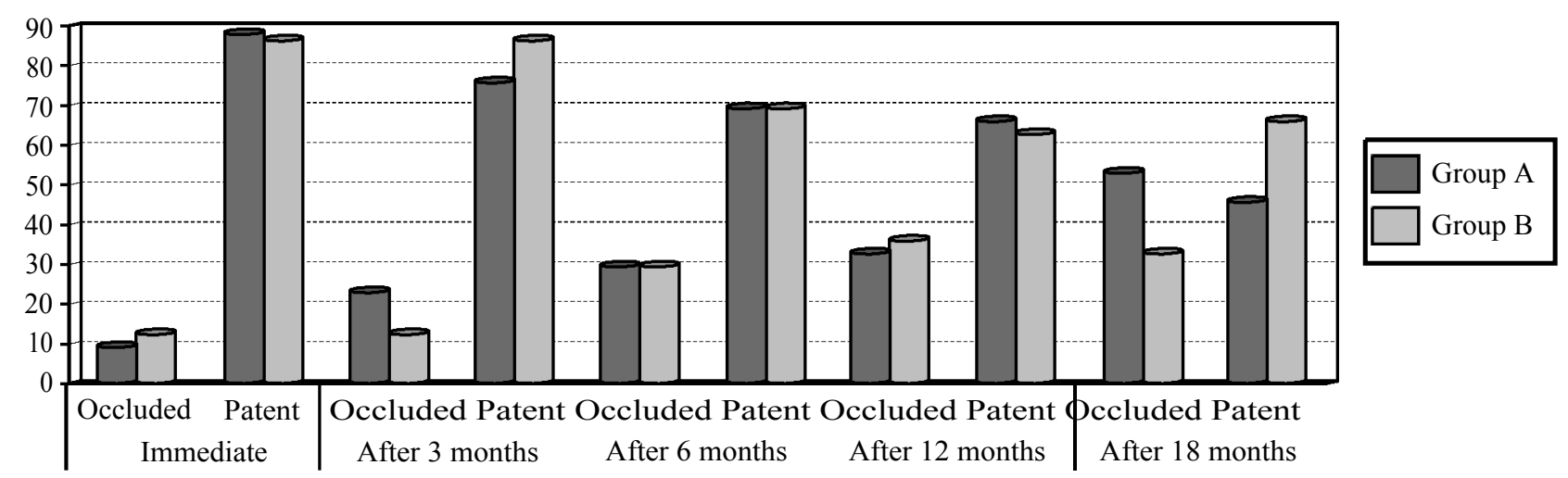

Graph. (7): Comparison between the two studied groups according to patency. 
Table (8): Comparison between the two studied groups according to complications.

\begin{tabular}{lllll}
\hline \multirow{2}{*}{ Complications } & $\begin{array}{c}\text { Group A } \\
(\mathrm{n}=30 \\
\end{array}$ & $\begin{array}{c}\text { Group B } \\
\text { limbs })\end{array}$ & $\begin{array}{c}(\mathrm{n}=30 \\
\text { limbs })\end{array}$ \\
\cline { 2 - 5 } & No. & $\%$ & No. & $\%$ \\
\hline Amputations & 7 & 23.3 & 4 & 13.3 \\
& $\chi$ & 0.625 & $p=0.695$ \\
Major: & 7 & 23.3 & 1 & 3.3 \\
- Acute thrombosis & 3 & 10.0 & 0 & 0.0 \\
- Sever graft infection & 2 & 6.7 & 0 & 0.0 \\
- Huge hematoma \& pseudo-aneurysm & 2 & 6.7 & 1 & 5.0 \\
Minor: & 12 & 40.0 & 4 & 13.3 \\
- Edema & 6 & 20 & 0 & 0.0 \\
- Infection & 3 & 10 & 0 & 0.0 \\
- Hematoma & 2 & 6.7 & 4 & 13.3 \\
- Contracture scar at knee & 1 & 3.3 & 0 & 0.0 \\
\hline
\end{tabular}

\section{Discussion}

The treatment of CLI has changed and continued clinical and research work is focused on which intervention is more effective. Since the shift from open surgery to endovascular treatment of CLI, there remains controversy regarding the optimal treatment approach to this disease process. Those who argue for an 'open first' approach emphasize the durability of the approach, shorter healing times for tissue loss and similar morbidity to endovascular therapy when 'minimally invasive' open approaches are used. Open procedures, specifically autogenous vein bypasses, have been observed to have higher patency than endovascular procedures at similar time points [7]

The 'endo first' approach is also often based on the limited life expectancy of many of these patients, who have co-morbidities such as diabetes or renal failure. Furthermore, they propose the position that an endovascular approach still allows for open surgery for those who fail percutaneous intervention and that the subsequent open procedure will not be modified by preceding endovascular attempts [3]

As regard patients demographic data; in this study: $29(72.5 \%)$ males and $11(27.5 \%)$ females with age over 40 years with strata; $41-50$ years: 13 (32.5\%), 51-60 years: $27(67.5 \%)$ and $>60$ years: $19(47.5 \%)$; this was comparable to study done by Aboulela [16] that included 32 were treated with percutaneous transluminal balloon angioplasty, with mean age 61 years 26 males $(81.2 \%)$ and 6 females $(18.8 \%)$. But less than study done by Soderstrom et al., [8] that involved 86 consecutive patients, 62 males ( $72.1 \%$ ), median age 71 years, undergoing infrageniculate bypass grafting for CLI.

The presenting symptoms were: In group A: 5 patients $(25 \%)$ had rest pain (Rutherford 4), 10 patients $(50 \%)$ had minor tissue loss (Rutherford 5 ) and 5 patients (25\%) had major tissue loss (Rutherford 6). In Group B: 4 patients (20\%) had rest pain (Rutherford 4), 10 patients $(50 \%)$ had minor tissue loss (Rutherford 5) and 6 patients (30\%) had major tissue loss (Rutherford 6). As describe by Aboulela [16] who distribute 32 patients; Rutherford category 4 (rest pain) was in 6 patients and Rutherford category 5 (minor tissue loss) was in 16 patients and Rutherford category 6 (major tissue loss) was in 10 patients.

Given the concern of patients classification according to lesion morphology through TASC lesion classification 2015 into TASC A, B, C and $D$ as: In Group A: No patient with TASC A classification, 4 patients (20\%) with TASC B classification, 10 patients $(50 \%)$ with TASC C classification, 6 patients (30\%) with TASC D lesion classification. In Group B: 3 patients (15\%) with TASC A classification, 5 patients $(25 \%)$ with TASC B classification, 7 patients $(35 \%)$ with TASC C classification, 5 patients $(25 \%)$ with TASC D lesion classification.

Sayed \& Elkashef [17] indication of revascularization in Group (A) were 7 patients presented by gangrene $53 \%, 4$ by rest pain $30 \%$ and 2 by foot infection $15 \%$. In Group (B) were 8 patients presented by gangrene $57 \%, 4$ by rest pain $29 \%$ and 1 by foot infection $7 \%$. Indications for arterial reconstruction were rest pain in $16(18.6 \%)$ and tissue loss in $70(81.4 \%)$ patients.

Patients involved in this study had multiple risk factors and co-morbidities as: 27 patients $(67.5 \%)$ were smokers, 31 patients $(77.5 \%)$ were diabetics, 29 patients $(72.5 \%)$ were hypertensive (HTN), 19 patients $(47.5 \%)$ were ischemic heart disease (IHD), 24 patients (60\%) had hyperlipidemia (HLIP), 5 patients (12.5\%) had previous stroke and 11 patients $(27.5 \%)$ had previous peripheral angioplasty. This was comparable to study done by Soderstrom et al., [8] who reported that risk factors were diabetes mellitus in $53(61.6 \%)$, smoking in 34 (39.5\%), hyperlipidemia in 48 $(55.8 \%)$, and hypertension in $77(89.5 \%)$ patients. Aboulela [16] risk factors were diabetes in 20 patients "62.5\%", smoking in 20 patients (62.5\%), Ischemic Heart Disease (IHD) in 18 patients $(56.2 \%)$, hypertension in 16 patients $(50 \%)$ and hyperlipidemia in 16 patients $(50 \%)$. 
Upon review of the patency rates in this study; immediate, after 3, 6, 12 and 18 months patency was $90.0 \%, 76.7 \%, 70.0 \%, 66.7 \%, 46.7 \%$ in Group (A) respectively vs. $86.7 \%, 86.7 \%, 70.0 \%, 63.3 \%$, $66.7 \%$ in Group (B) respectively; the results of Group (A) was similar to results mentioned by Illuminati et al., [18] who reported primary patency rate with PTFE graft for infrapopliteal bypass $67 \%$ at 2 years and $43 \%$ at 3 years, Albers et al., [19] who showed primary success $93 \%$ with limb salvage $88 \%$ in a meta-analysis of 31 studies for distal bypass. And Neville et al., [20] who compared tibial bypass with heparin-bonded ePTFE vs saphenous vein and reported Primary patency based on conduit was HePTFE 75\% and Saphenous Vein Graft (SVG) patency $86 \%$ and Soderstrom et al., [8] who reported 1 -year primary success $79 \%$ with limb salvage $77 \%$. But the results of Group (B) was similar to results mentioned by Aboulela [16] who described the primary patency rates were 95 and 80 at 1 and 6 months respectively, Keeling et al., [21] who reported primary success rate $78 \%$ and limb salvage rate was 73\% in CLI group and Abd Allah [22] who reported immediate primary success rate $95 \%$ and $70 \%$ by the end of 1 st year after revascularization.

As regard to complications: In Group A 11 limbs $(36.7 \%)$ passed without complications and 19 limbs (63.3\%) underwent complications. In Group B 25 limbs (83.3\%) passed without complications and 5 patients $(16.7 \%)$ with complications. Regarding to amputations, 7 limbs (23.3\%) of Group A underwent major amputation, but in Group B 4 patients $(13.3 \%)$ underwent major amputation. This results were comparable to Chong et al., [13] who reported in surgical group morbidity was $29 \%$ in form of post revascularization edema and wound infection. But in endovascular group morbidity was $10 \%$ in form of wound hematoma $(n=4)$, and pseudoaneurysm $(n=4)$. Thromboembolic complications occurred in five patients with symptomatic deterioration. Mortality was $1 \%$ due to myocardial infarction, Schmidt A. et al., [23] who reported procedure-related complication rate for infrapopliteal angioplasty was $7.8 \%$ and was mostly due to groin hematoma, perforations, embolism, and acute occlusions and Abulela [16] from 32 patients There were 2 cases of post procedure groin hematoma and 2 cases of myocardial infarction during the first week after the procedure.

The results of the current study were quietly comparable to other mentioned studies. The differences between studies are probably related to technical experience, and selection criteria of patients and differences in the quality of the runoff,
This study included more patients with TASC A and $\mathrm{C}$.

\section{Conclusions:}

Due to innovations in endovascular techniques and as it is a minimal invasive; angioplasty became the first line of treatment of BK PAD. Endovascular intervention treat the lesion and keep the arterial tree with its native anatomical pattern so angioplasty can be done again if restenosis occur. Unlike surgical intervention in which it's too difficult to re-interfere after surgical bypass.

\section{References}

1- VAN OVERHAGEN H. and SPILIOPOULOS S.: Belowthe-knee intervention Cardiovasc. Intervent. Radiol., 36: 302-11, 2013.

2- BARGELLINI I., PETRUZZI P., SCATENA A., CIONI R., CICORELLI A. and VIGNALI C.: Primary infrainguinal subintimal angioplasty in diabetic patients. Cardiovasc Intervent Radiol., 31: 713-22, 2008.

3- WONG C., TANMAKET C. and CHANG A.: Angioplasty, balloon; Arterial occlusive diseases; Ischemia; Leg H. K. Med. J., 14: 139-74, 2009.

4- DOHMEN A., EDER S., EURINGER W., ZELLER T. and BEYERSDORF F.: Chronic critical limb ischemia Dtsch. Arztebl. Int., 109 (6): 95-101, 2012.

5- BRADBURY A., ADAM, D., BELL J., FORBES J., FOWKES M., GILLESPIE I. and RUCKLEY C.: BASIL Trial Participants 2010, 'Bypass versus Angioplasty in Severe Ischemia of the Leg (BASIL) trial: A survival prediction model to facilitate clinical decision making' Journal of Vascular Surgery, Vol. 51, pp. 52S-68S., 10.1016/j.jvs. 01.077, 2010.

6- ANDREW W.: Bypass vs. Angioplasty in Severe Ischaemia of Leg (BASIL) Trial: What Are Its Implications? Semin. Vasc. Surg., 22: 267-74, 2009.

7- MANZI M., PALENA L. and CESTER G.: Revascularization of Tibial and Foot Arteries: Below the Knee Angioplasty for Limb Salvage, Angioplasty, Various Techniques and Challenges in Treatment of Congenital and Acquired Vascular Stenoses, In Tech., 10: 209-37, 2012.

8- SODERSTROM M., ARVELA E. and KORHONEN M.: Infrapopliteal percutaneous transluminal angioplasty versus bypass surgery as first-line strategies in critical leg ischemia: A propensity score analysis. Ann. Surg., 252: 765-73, 2010 .

9- FAGLIA E., CLERICI G. and CLERISSI J.: When is a technically successful peripheral angioplasty effective in preventing above-the-ankle amputation in diabetic patients with critical limb ischemia? Diabet. Med., 24: 823-9, 2007.

10- ANDREW W., DONALD J., JOCELYN B., FORBES M., GERRY R. and FOWKES L.: On behalf of the BASIL trial participants, Birmingham and Edinburgh, United Kingdom Bypass versus Angioplasty in Severe Ischemia of the Leg (BASIL) trial: Analysis of amputation free and overall survival by treatment received. J. Vasc. Surg., 51: 18S-31S, 2010 
11-DANIEL B., JOANA F., ARMANDO M. and ANTÓNIO G.: Below the Knee techniques now and then. Angioplasty, Various Techniques and Challenges in Treatment of Congenital and acquired Vascular Stenoses, 953-51-0084-3, 2012.

12-BALAR N., DODLA R. and OZA P.: Endovascular versus open surgery for peripheral arterial disease. Endovascular Today, 61-4, 2011.

13- CHONG A., TAN C., WONG W. and CHENG S.: Bypass surgery or percutaneous transluminal angioplasty to treat critical lower limb ischemia due to infrainguinal arterial occlusive disease? Hong Kong Med. J., 15: 249-54, 2012.

14- STOMBERG M.W.: Postoperative pain management on surgical wards--do quality assurance strategies result in long-term effects on staff member attitudes and clinical outcomes? Pain Manag. Nurs., 4 (1): p. 11-22, 2003.

15- GAGLIESE L.: The measurement of postoperative pain: A comparison of intensity scales in younger and older surgical patients. Pain, 117 (3): p. 412-20, 2005.

16- ABULELA A.: Assessment of the Outcome of the Infragenicular Balloon Angioplasty for Limb Salvage in Patients with Critical Lower Limb Ischemia (Cli), Journal of American Science, 8 (6), 2012.

17- SAYED A. and ELKASHEF O.: Popliteal-to-Distal (PD) Bypass vs. Infrapopliteal PTA: What Is the Appropriate
Treatment for Infrapopliteal Disease? Kasr El-Aini Journal of Surgery, 8 (2):1-10, 2007.

18- ILLUMINATI G., BERTANGI A. and FORBES M. Distal polytetrafluoroethylene bypasses in patients older than 75 years. Arch. Surg., 135: 780-4, 2000.

19- ALBERS M., ROMITI M., CARDOSO F., NETO B., De LUCCIA N. and PEREIRA C.: Meta-analysis of poplitealto-distal vein bypass grafts for critical ischemia. J. Vasc. Surg., 43: 498-503, 2006.

20- NEVILLE R., TEMPESTA B. and SIDWAY A.: Tibial bypass for limb salvage using polytetrafluoroethylene and a distal vein patch. J. Vasc. Surg., 33: 266-71; discussion 271-2, 2010 .

21- KEELING N., KHALIDI K. and SUM LEONG S.: Below knee angioplasty in elderly patients: Predictors of major adverse clinical outcomes. European Journal of Radiology, 77: 483-9, 2010.

22- ABD ALLAH A: Assessment of the outcome of the infragenicular balloon angioplasty for limb salvage in patients with critical lower limb ischemia. Egyptian Journal of Surgery, 31 (2): 72-8, 2012

23- SCHMIDT A., ULRICH M., WINKLER B., KLAEFFLING C. and BAUSBACK Y.: Angiographic patency and clinical outcome after balloon-angioplasty for extensive infrapopliteal arterial disease. Catheter Cardiovasc. Interv., 76: 1047-54, 2010. 


\section{كيف يمكن تحقيق أفضل النتائج فى علاج مرض الإنسل ادهاد القصبى

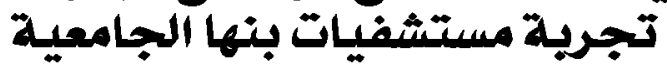

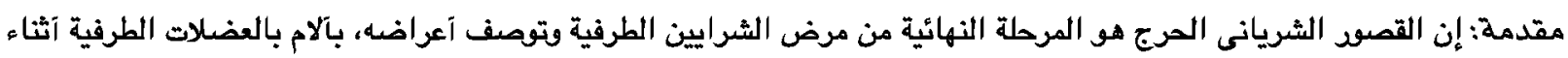

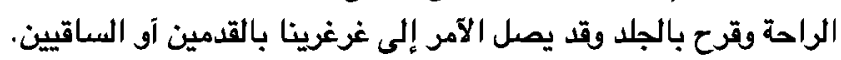

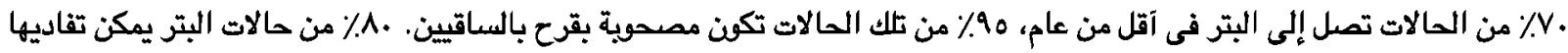

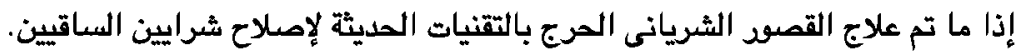

الهدف من العلاج هو السيطرة على الآلام والعمل على إلتئام الجروح والقرح وإنقاذ الطرف من البتر والحفاظ على العى وظيفته. هناك طريقتين

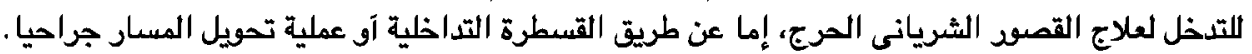

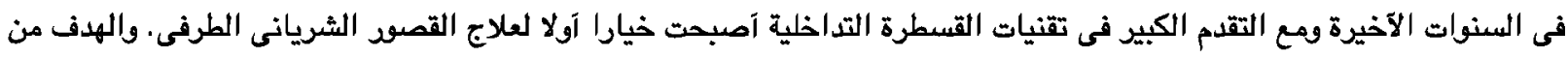

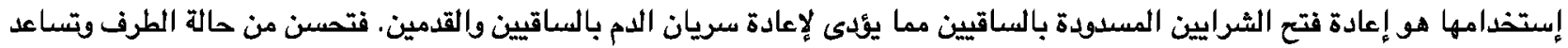
على إلتئام الجرح وتقليل الآلام المسيبة بالقصود الثرين الثريانى.

بينما يظل التدخل الجراحى حلا جيدا لعلاج القصود الشريانى الطرفى عن طريق عملية تحويل المسار. تقدم القسطرة التداخلية إمكانية التدخل بتخدير موضعى وتقليل مدة حجز المريض بالمستشفى وتقلل من التعرض للآخطار المصاحبة الجراحات الكرات الكبرى.

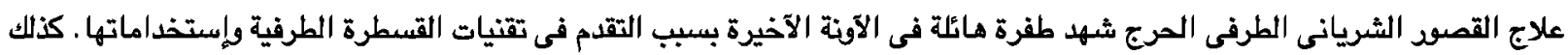

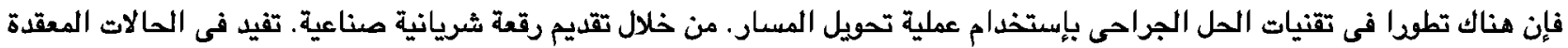

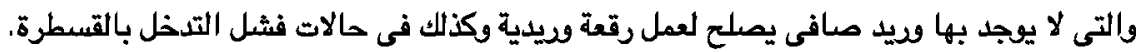

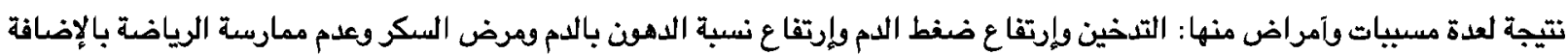

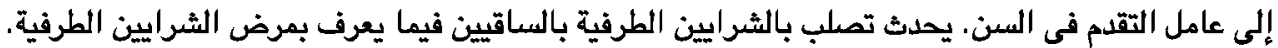

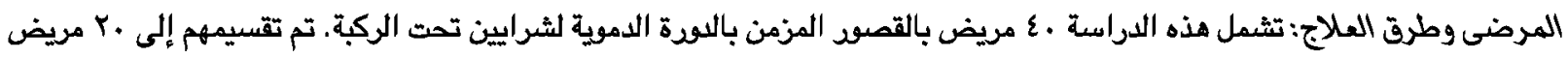

تلقوا العلاج الجراحى بتحويل المسار للشرايين الطرفية و.r مريض تلقوا العلاج عن طريق القسطرة التداخلية بمستشفيات جامعة بنها.

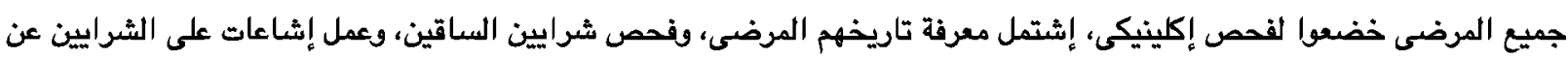
طريق الموجات فوق الصوتية على الشرايين، آو آشعة مقطعية بالصبغة، آو رنين مفناطيسى على شرائين شعلين الساقين.

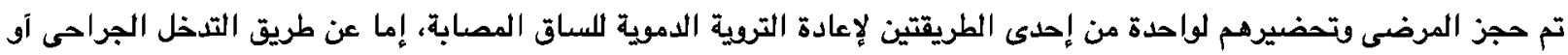

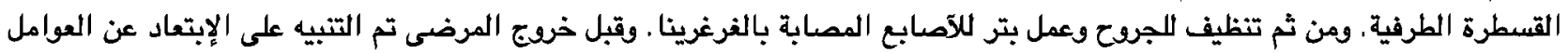

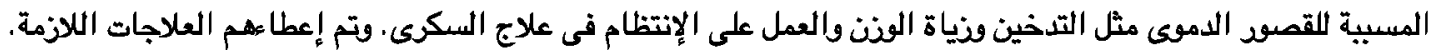

